\section{Impact of plasmatic lipids in glycemic control and its influence in the cardiometabolic risk in morbidly obese subjects}

\author{
Impacto dos lipídios plasmáticos no controle glicêmico e sua \\ influência no risco cardiometabólico em pacientes obesos mórbidos
}

Ary Serpa Neto', Felipe Martin Bianco Rossi', Rodrigo Dal Moro Amarante' ${ }^{1}$ Nara Alves Buriti', Marçal Rossi²

\begin{abstract}
Objectives: To evaluate whether biochemical parameters are associated with a good glycemic control and to identify the occurrence of cardiometabolic risk variables. Material and methods: One hundred forty Brazilians were evaluated. The subjects were characterized with regard to glycemic control as good, fair and poor and were divided into tertiles by TG and $\mathrm{HbA}_{1 \mathrm{c}}$. We use the ROC curve to determine which variables were predicted of poor glycemic control and the factor analyses to identify the domains that segregated among the risk variables. Results: Fasting glucose and insulin levels, TG level, VLDL-C and HOMA-IR increased significantly across $\mathrm{HbA}_{1 \mathrm{c}}$ tertiles. The best marker for identification of poor glycemic control was triglycerides. The presence of cardiometabolic abnormalities did not alter the glycemic control, but HOMA-IR was significantly higher in subjects with abnormalities. Conclusion: The use of TG levels offers a reasonable degree of clinical utility. In morbidly obese subjects insulin resistance is associated with individual cardiometabolic factors. Arq Bras Endocrinol Metab. 2009;53(6):747-54
\end{abstract}

Keywords

Obesity; blood glucose; bariatric surgery; diabetes mellitus

\section{RESUMO}

Objetivos: Avaliar o quanto os lipídios plasmáticos, o IMC e a glicemia de jejum estão associados com um bom controle glicêmico e identificar a ocorrência de variáveis do risco cardiometabólico. Método: Cento e quarenta brasileiros foram avaliados. Os pacientes foram caracterizados, de acordo com o controle glicêmico, como tendo bom controle, moderado controle e controle ruim e foram divididos em tercis de TG e $\mathrm{HbA}_{1 c}$. Utilizou-se a curva ROC para determinar quais variáveis predizem um controle glicêmico inadequado e a análise fatorial para identificar os domínios que segregam as diferentes variáveis. Resultados: A glicemia de jejum e os níveis de insulina, os níveis de TG, VLDL-C e HOMA-IR aumentaram significativamente de acordo com os tercis de $\mathrm{HbA}_{1 \mathrm{c}}$. $\mathrm{O}$ melhor marcador para identificação de indivíduos com um controle glicêmico ruim foi o triglicérides. A presença de anormalidades cardiometabólicas não alterou significativamente o controle glicêmico, mas o HOMA-IR foi significativamente maior nestes indivíduos. Conclusão: $\mathrm{O}$ uso dos níveis deTG oferece uma boa utilidade clínica. Em pacientes obesos mórbidos, a resistência à insulina esta associada com fatores de risco cardiometabólico. AArq Bras Endocrinol Metab. 2009;53(6):747-54

Descritores

Obesidade; glicemia; cirurgia bariátrica; diabetes melito
${ }^{1}$ Divisão de Tratamento Clínico e Cirúrgico da Obesidade, Faculdade de Medicina do ABC (FMABC), Santo André, SP, Brasil ${ }^{2}$ Sociedade Brasileira de Cirurgia Bariátrica e Metabólica (SBCBM), São Paulo, SP, Brasil

Correspondence to: Ary Serpa Neto

Av. Lauro Gomes, 2000 09060-870 - Santo André, SP, Brasil aryserpa@terra.com.br

Received in Mar/19/2009 Accepted in Apr/23/2009

\section{INTRODUCTION}

$\mathrm{T}$ The diabetic complications can be prevented or delayed by tight glycemic control. The American Dia- betes Association (ADA) recommend $\mathrm{HbA}_{\mathrm{lc}}$ less than $7 \%$ as glycemic goal for non-pregnant diabetic pacients (1). Even in patients who cannot achieve the goal, 
improved glycemic control is still associated with decreased rates of microvascular complications (2-3). In obese patients, the presence of type 2 diabetes (DM2) is a major risk factor for cardiovascular diseases and the impaired glucose tolerance (IGT) is considered to be an independent risk factor for macrovascular complications (4). Thus, in morbidly obese patients, the glycemic control has to be more intensive.

Glycemic control depends mainly on the degree of residual pancreatic beta-cell function and insulin sensitivity (5). A number of clinical features are associated with these two factors, such as body mass index (BMI), waist circumference, plasma triglycerides as well as HDL-cholesterol, all factors related to insulin resistance (6). In one investigation, McLaughlin and cols. found that in subjects with a BMI of $25 \mathrm{~kg} / \mathrm{m}^{2}$ or more, the lipid criteria, specifically triglycerides (TG) levels and TG-HDL-C ratio, were sensitivity markers of insulin resistance (7). They found that the cut offs for the lipid criteria that were most predictive of insulin resistance were TG level of $130 \mathrm{mg} / \mathrm{dL}$ or more and/ or TG-HDL-C ratio of 3 or more.

The cardiometabolic risk encompasses a cluster of modifiable classic and emerging risk factors and markers that identify individuals at increased risk for cardiovascular disease and type 2 diabetes (8). It includes the factors that make up the National Cholesterol Education Program's Adult Treatment Panel III (NCEP-ATPIII) definition of metabolic syndrome and encompasses four additional factors: smoking, elevated LDL-C, inflammatory markers and insulin resistance (8-9). In a classical study, Meigs and cols. identified three factors underlying the clustering of certain risk variables. The first cluster includes insulin levels, triglycerides and HDL-C levels, BMI and waist-to-hip ratio, all of which were associated with metabolic syndrome. The second cluster includes glucose and insulin levels which are associated with impaired glucose tolerance. The third cluster includes systolic and diastolic blood pressure and BMI, factors that are associated with hypertension (10).

The primary purpose of the present study was to evaluate whether plasmatic lipids, BMI and fasting glucose are associated with a good glycemic control. In the secondary aim of this study, we investigated the occurrence of cardiometabolic risk variables, the distribution of insulin resistance and its association with the individual cardiometabolic risk variables and how cardiometabolic risk factors cluster and how much of such clustering may be associated with insulin resistance in morbidly obese subjects.

\section{METHODS}

\section{Study population}

One hundred and forty Brazilians (29 men and 111 women), with a mean age of $34 \pm 8$ years and a mean BMI of $45 \pm 4 \mathrm{~kg} / \mathrm{m}^{2}$ were evaluated. Patients on insulin treatment, as well as those with liver or kidney disease and diabetes mellitus type 1 were excluded. Blood samples were drawn in the morning after an overnight fast (minimum of eight hours) and the biochemical parameters were analyzed as the standard. Insulin resistance was calculated using the homeostasis model assessment (11). The subjects were characterized with regard to glycemic control as good $\left(\mathrm{HbA}_{1 \mathrm{c}}<7 \%, \mathrm{n}=42\right)$, fair $\left(\mathrm{HbA}_{\mathrm{lc}} 7\right.$ to $\left.8 \%, \mathrm{n}=64\right)$ and poor $\left(\mathrm{HbA}_{\mathrm{lc}}>8 \%, \mathrm{n}=\right.$ 34). To assess the effect of weight loss in cardiometabolic risk, the patients underwent laparoscopic Rouxen-Y gastric bypass (RYGBP), and after eight months all the tests were repeated. All procedures were carried out at Faculdade de Medicina do ABC (FMABC) and affiliated institutions.

The normal cut off values for anthropometric, lipid and blood pressure parameters used in this study was the criteria used by the International Diabetes Federation: waist circumference $\geq 94 \mathrm{~cm}$ in men, $\geq 80 \mathrm{~cm}$ in women or BMI $\geq 30 \mathrm{~kg} / \mathrm{m}^{2}$; triglycerides levels $\geq 150 \mathrm{mg} / \mathrm{dL}(1.7 \mathrm{mmol} / \mathrm{L})$ and/or specific treatment; HDL-C levels $<40 \mathrm{mg} / \mathrm{dL}(1 \mathrm{mmol} / \mathrm{L})$ in men, $<50 \mathrm{mg} / \mathrm{dL}(1.3 \mathrm{mmol} / \mathrm{L})$ in women and/or specific treatment; fasting glucose $(\mathrm{FG}) \geq 100 \mathrm{mg} / \mathrm{dL}(5.6$ $\mathrm{mmol} / \mathrm{L}$ ) and/or DM2 patient; systolic blood pressure $\geq 130 \mathrm{mmHg}$, diastolic blood pressure $\geq 85 \mathrm{mmHg}$ and/or specific treatment (9). The patients were divided into tertiles by $\mathrm{TG}$ and $\mathrm{HbA}_{1 \mathrm{c}}$; these tertiles were, respectively: 512 to $150 ; 10.9$ to $7.7,148$ to $105 ; 7.6$ to 7 and 104 to $43 \mathrm{mg} / \mathrm{dL} ; 6.9$ to $5.4 \%$.

\section{Statistical analysis}

Data are presented as mean \pm SD. Because results did not vary when adjusted for sex, combined results were presented. Linear regression and stepwise multiple regression analyses were performed to evaluate the relationship among $\mathrm{HbA}_{\mathrm{lc}}$, plasmatic lipids, BMI and fasting glucose levels. Tertile distributions of the patients were compared by 1 -way analysis of variance (ANOVA) with Tukey corrections for multiple comparisons. Categorical data were analyzed with $\chi^{2}$ test. Areas under the receiver-operating characteristics (ROC) curves 
were determined for each variable to identify which were predictors of poor glycemic control. Areas under the ROC curve are provided with standard errors. An ROC curve is a plot of sensitivity (true positive) versus l-specificity (false positive) for each potential marker.

Pearson's correlation coefficients were computed in order to explore the correlations between two variables. Factor analyses with principal component analyses (PCA) were used to identify the domains that segregated among the risk variables (12). The risk variables included fasting plasma glucose and insulin, HDL-C, HOMA-IR, $\mathrm{HbA}_{1 \mathrm{c}}$, triglycerides, waist-to-hip ratio and BMI. PCA method with orthogonal rotation identifies subsets of clusters of correlated variables. Interpretation was based on the correlations called loadings (range - 1.0 to 1.0) between the factors and the original independent variables greater than \pm 0.30 to interpret the resulting factor pattern (12).
All statistical analyses were made with the statistical software package SPSS (v 15.0; SPSS, Chicago, IL), MedCalc software and ROCKIT 0.9B (Department of Radiology from The University of Chicago). Statistical significance was considered at $\mathrm{p}<0.05$.

\section{RESULTS}

\section{Association between glycemic control and biochemical parameters}

The tertiles of TG and $\mathrm{HbA}_{1 \mathrm{c}}$ were determined on the basis of the studied population of 140 individuals. Of these, for triglycerides and $\mathrm{HbA}_{\mathrm{lc}}$ respectively, 45 and 42 were in the first tertile, 35 and 46 were in the second and 60 and 52 were in the third (Table 1). The HOMA-IR increased across the triglycerides tertiles and in the third tertile (upper limit) it was significantly higher than in the first tertile (inferior limit). For the

\begin{tabular}{|c|c|c|c|c|c|c|}
\hline & \multicolumn{6}{|c|}{ Triglycerides } \\
\hline & $\begin{array}{l}\text { Tertile } 1 \\
(n=45)\end{array}$ & $\mathbf{p}^{\mathrm{a}}$ & $\begin{array}{l}\text { Tertile } 2 \\
(\mathrm{n}=35)\end{array}$ & $\mathbf{p}^{b}$ & $\begin{array}{l}\text { Tertile } 3 \\
(n=60)\end{array}$ & $\mathbf{p}^{\mathrm{c}}$ \\
\hline Age (years) & $37.4 \pm 10$ & 996 & $37.2 \pm 10$ & 999 & $37.3 \pm 9$ & 998 \\
\hline $\mathrm{BMI}\left(\mathrm{kg} / \mathrm{m}^{2}\right)$ & $44.1 \pm 4$ & 982 & $43.9 \pm 4$ & 908 & $44.3 \pm 4$ & 967 \\
\hline Fasting insulin $(\mu \mathrm{U} / \mathrm{L})$ & $13.3 \pm 1$ & 644 & $13.9 \pm 3$ & 466 & $14.6 \pm 3$ & 060 \\
\hline Fasting glucose (mg/dL) & $92.7 \pm 10$ & 597 & $97.9 \pm 29$ & 413 & $104.3 \pm 26$ & $038^{*}$ \\
\hline HOMA-IR & $3.0 \pm 0$ & 437 & $3.5 \pm 2$ & 528 & $3.9 \pm 2$ & $030^{*}$ \\
\hline $\mathrm{HbA}_{1 \mathrm{c}}(\%)$ & $6.8 \pm 0$ & 169 & $7.1 \pm 0$ & $000^{*}$ & $8.3 \pm 0$ & $000^{*}$ \\
\hline $\mathrm{HDL}-\mathrm{C}(\mathrm{mg} / \mathrm{dL})$ & $47.9 \pm 12$ & 685 & $45.9 \pm 9$ & 714 & $47.7 \pm 10$ & 994 \\
\hline$\%$ metabolic syndrome & 44.4 & $033^{*}$ & 57.1 & 712 & 60 & $003^{\star}$ \\
\hline \multirow[t]{3}{*}{$\%$ lipid criteria } & 44.4 & $000^{*}$ & 68.6 & $000^{*}$ & 100 & $000^{*}$ \\
\hline & \multicolumn{6}{|c|}{$\mathrm{HbA}_{1 \mathrm{c}}$} \\
\hline & $\begin{array}{l}\text { Tertile } 1 \\
(\mathrm{n}=42)\end{array}$ & $\mathbf{p}^{\mathrm{a}}$ & $\begin{array}{l}\text { Tertile } 2 \\
(\mathrm{n}=46)\end{array}$ & $\mathbf{p}^{b}$ & $\begin{array}{l}\text { Tertile } 3 \\
(n=52)\end{array}$ & $\mathbf{p}^{\mathrm{c}}$ \\
\hline Age (years) & $36.3 \pm 10$ & 941 & $35.6 \pm 9$ & 120 & $39.6 \pm 10$ & 252 \\
\hline BMI $\left(\mathrm{kg} / \mathrm{m}^{2}\right)$ & $43.9 \pm 4$ & 896 & $43.5 \pm 3$ & 302 & $44.8 \pm 4$ & 586 \\
\hline Fasting insulin $(\mu \mathrm{U} / \mathrm{L})$ & $12.4 \pm 1$ & 146 & $13.5 \pm 1$ & $000^{*}$ & $15.8 \pm 3$ & $000^{\star}$ \\
\hline Fasting glucose (mg/dL) & $84.8 \pm 7$ & 093 & $94 \pm 9$ & $000^{*}$ & $114.7 \pm 31$ & $000^{*}$ \\
\hline HOMA-IR & $2.6 \pm 0$ & 232 & $3.1 \pm 0$ & $000^{*}$ & $4.7 \pm 2$ & $000^{\star}$ \\
\hline $\mathrm{TG}(\mathrm{mg} / \mathrm{dL})$ & $97 \pm 32$ & 093 & $125.5 \pm 37$ & $000^{*}$ & $231.8 \pm 93$ & $000^{\star}$ \\
\hline TG-HDL-C ratio & $3.3 \pm 1$ & 903 & $3.6 \pm 2$ & 993 & $3.5 \pm 2$ & 940 \\
\hline $\mathrm{HDL}-\mathrm{C}$ (mg/dL) & $49.7 \pm 11$ & 644 & $47.6 \pm 11$ & 523 & $45.2 \pm 9$ & 120 \\
\hline VLDL-C (mg/dL) & $24.6 \pm 11$ & 517 & $27.3 \pm 9$ & $000^{*}$ & $41.7 \pm 13$ & $000^{*}$ \\
\hline LDL-C (mg/dL) & $111.3 \pm 36$ & 176 & $125.5 \pm 35$ & 965 & $127.4 \pm 39$ & 095 \\
\hline$\%$ metabolic syndrome & 54.8 & 057 & 47.8 & $047^{*}$ & 59.6 & 062 \\
\hline$\%$ lipid criteria & 47.6 & $000^{*}$ & 78.3 & $003^{*}$ & 92.3 & $000^{*}$ \\
\hline
\end{tabular}


$\mathrm{HbA}_{\mathrm{lc}}$ group, fasting glucose and insulin levels, TG level, VLDL-C and HOMA-IR increased significantly across tertiles.

The sensitivity, specificity and positive likelihood ratio $(+\mathrm{LR})$ value of the metabolic syndrome to diagnose poor glycemic control in Brazilians were 45\%, 54.7\% and $1.02 \%$ respectively. For the lipid criteria, the sensitivity, specificity and + LR to identify individuals with poor glycemic control were, respectively, $85 \%, 52 \%$ and $1.8 \%$.

The Figure 1 shows the ROC curve for all potential metabolic markers evaluated. The best markers for identification of individuals with poor glycemic control were, in rank-ordered, triglycerides, fasting glucose and fasting insulin, and the AUC of these markers were significantly greater than those of the other three markers (Table 2). The sensitivity and the specificity for these markers were, respectively, 62,63 and $36 \%$ and 97,88 and $100 \%$.

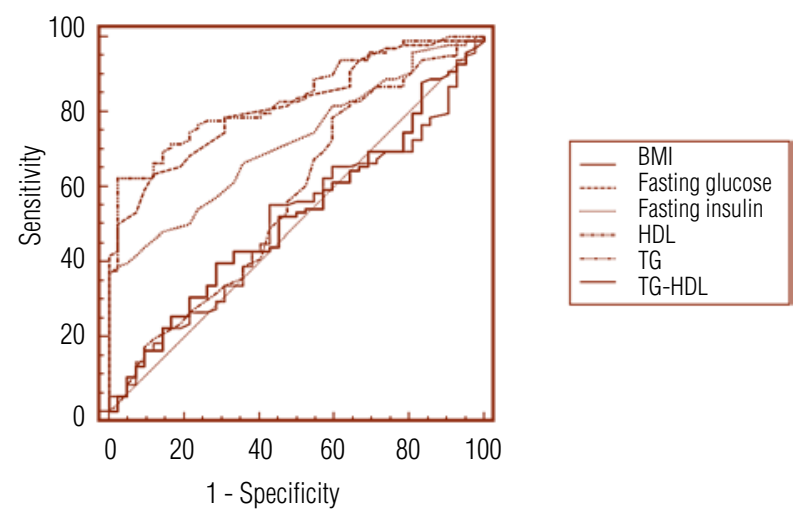

Figure 1. Receiver-operating characteristic curves for metabolic markers of poor glycemic control.

Table 2. Comparison of areas under ROC curves (AUC) for parameters that are potentials markers of poor glycemic control

\begin{tabular}{lcc}
\hline Variable & AUC (Mean \pm SE) & 95\% Confidence interval \\
\hline BMI & $0.518 \pm 0.05$ & $0.432-0.603$ \\
Fasting glucose & $0.815 \pm 0.03$ & $0.741-0.876$ \\
Fasting insulin & $0.719 \pm 0.04$ & $0.637-0.792$ \\
HDL-C & $0.571 \pm 0.05$ & $0.485-0.654$ \\
Triglycerides & $0.837 \pm 0.03$ & $0.765-0.894$ \\
TG-HDL-C Ratio & $0.505 \pm 0.05$ & $0.419-0.590$ \\
\hline
\end{tabular}

To test these results, the relative ability of the cut off values found for the triglycerides, fasting glucose and insulin were compared in order to identify individuals with good or poor glycemic control. It can be seen, in Table 3, that a high TG level (> $146 \mathrm{mg} / \mathrm{dL}$ ) identified $62.2 \%$ of the individuals with poor glycemic control (PGC), and a low TG $(\leq 146 \mathrm{mg} / \mathrm{dL})$ identified $95.2 \%$ of the individuals with good glycemic control (GGC) $\left(\chi^{2}=39.2, \mathrm{p}<0.0001\right)$. Similarly, a high fasting glucose level correctly identified $65.3 \%$ of the patients with PGC, and a low FG identified $81 \%$ of the patients with GGC $\left(\chi^{2}=25.1, \mathrm{p}<0.0001\right)$. Quite the opposite, high levels of fasting insulin identified only $38.8 \%$ of individuals with PGC, but the low levels correctly identified $97.6 \%$ of individuals with GGC $\left(\chi^{2}=19.3, \mathrm{p}<0.0001\right)$.

$\mathrm{HbA}_{\mathrm{lc}}$ was significantly correlated with fasting glucose and insulin levels, triglycerides level, HOMA-IR and HDL-C level (Pearson's correlation coefficients = $0.709,0.652,0.707,0.694$ and -0.398 , respectively). To assess the relative contribution of these parameters in the prediction of $\mathrm{HbA}_{\mathrm{lc}}$, we performed multiple stepwise linear regression analyses with $\mathrm{HbA}_{\mathrm{lc}}$ as dependent variable and FG, FI, TG, HOMA-IR, HDL-C and BMI as the independent variables. The results of these analyses indicated that, in the regression model, both FG and TG significantly predicted $\mathrm{HbA}_{\mathrm{lc}}$ (FG, $\beta$ $=0.29, \mathrm{p}<0.0001 ; \mathrm{TG}, \beta=0.21, \mathrm{p}<0.0001)$. The others parameters did not significantly contribute to the model.

\section{Assessment of cardiometabolic risks}

We found that, before RYGBP, $14.2 \%$ of the subjects could be include in all of the three physiologic domains of the insulin resistance syndrome and, after the surgery, this prevalence down to $7.1 \%(\mathrm{p}<0.05)$. Thus, before the surgery, only $10.7 \%$ of the patients had none factor and, after the procedure, this number increased to $27.1 \%(\mathrm{p}<0.05)$ (Table 4$)$.

The prevalence of cardiometabolic risk factors is shown in Table 5. Median values of HOMA-IR were significantly higher in subjects with abnormal values for

Table 3. Ability of triglycerides, fasting glucose and fasting insulin to identify individuals with poor or good glycemic control

\begin{tabular}{lcccccc}
\hline & TG 146 & TG $>$ 146 & FG $<$ 92 & FG > 92 & FI $<\mathbf{1 5 . 3}$ & FI > 15.3 \\
\hline PGC $(n=98)$ & $37(37.8 \%)$ & $61(62.2 \%)$ & $34(34.7 \%)$ & $64(65.3 \%)$ & $60(61.2 \%)$ & $38(38.8 \%)$ \\
GGC $(n=42)$ & $40(95.2 \%)$ & $2(4.8 \%)$ & $34(81 \%)$ & $8(19 \%)$ & $41(97.6 \%)$ & $1(2.4 \%)$
\end{tabular}

TG: triglycerides (mg/dL); FG: fasting glucose (mg/dL); Fl: fasting insulin ( $\mu \mathrm{U} / \mathrm{L})$; PGC: poor glycemic control (HbA $>$ $>7 \%$ ); GGC: good glycemic control (HbA $\leq 7 \%)$. 
each parameter, except in the HDL and in the smokers group. The presence of cardiometabolic abnormalities did not altered significantly the glycemic control, only in the LDL group. In the triglycerides and in the fasting glucose group, the relationship approach's significance $(\mathrm{p}=0.073$ and $\mathrm{p}=0.191$, respectively).

Principal axis factor analysis with varimax rotation was conducted to assess the underlying structure for six parameters. We identified two dominant factors that explained $56.1 \%$ of the total variance of data. After rotation, the first and the second factors accounted for 32.97 and $23.13 \%$ of the variance, respectively (Table 6). In the first factor, called glucose factor, fasting glucose and insulin levels had positive loadings. In the second factor, called lipid factor, LDL-C and triglycerides had positive loading and HDL had negative loading. Lipid profile was linked to the glucose factor by shared correlations with fasting glucose.

\begin{tabular}{lccc}
\hline \multicolumn{2}{l}{ Table 4. Prevalence of physiological domains of the insulin resistance syndrome, before and after RYGBP, based on the study by Meigs and cols. (10) } \\
\hline & Before & After & p \\
\hline None & $15(10.7 \%)$ & $38(27.1 \%)$ & $<0.05$ \\
Factor one onlya & $53(37.8 \%)$ & $56(40 \%)$ & $>0.05$ \\
Factor two only & $0(0 \%)$ & $1(0.7 \%)$ & $>0.05$ \\
Factor three only & $16(11.4 \%)$ & $11(7.8 \%)$ & $>0.05$ \\
Factor one and three & $30(21.4 \%)$ & $16(11.4 \%)$ & $<0.01$ \\
Factor one and two & $6(4.2 \%)$ & $8(5.7 \%)$ & $>0.05$ \\
Factor one, two and three & $20(14.2 \%)$ & $10(7.1)$ & $<0.05$ \\
\hline
\end{tabular}

No $(0 \%)$ individuals were classified as indeterminate (factor two and three).

a To estimate prevalence, the factor one was defined as the presence of at least two of the three characteristics: hiperinsulinemia (a fasting insulin level exceeding the $90^{\text {th }}$ percentile of its distribution among subjects with normal glucose tolerance), dyslipidemia (either a low HDL-C or an elevated triglyceride level) or obesity (either central or BMl $\geq 30 \mathrm{~kg} / \mathrm{m}^{2}$ ).

\begin{tabular}{|c|c|c|c|c|c|}
\hline & \multirow{2}{*}{ Prevalence } & \multicolumn{2}{|c|}{$\begin{array}{l}\text { HOMA-IR (SI) } \\
\text { (Mean } \pm \text { SD) }\end{array}$} & \multicolumn{2}{|c|}{$\begin{array}{c}\mathrm{HbA}_{1 \mathrm{c}}(\%) \\
(\text { Mean } \pm \text { SD) }\end{array}$} \\
\hline & & Presence & Absence & Presence & Absence \\
\hline HDL-C ${ }^{a}$ & $80(57.1 \%)$ & $3.55 \pm 2.0$ & $3.64 \pm 1.5$ & $7.59 \pm 1.1$ & $7.50 \pm 1.1$ \\
\hline Triglycerides ${ }^{a}$ & $60(42.9 \%)$ & $3.98 \pm 2.0$ & $3.29 \pm 1.5^{\star}$ & $7.75 \pm 1.1$ & $7.41 \pm 1.0$ \\
\hline Hypertensiona & $66(47.1 \%)$ & $4.05 \pm 2.0$ & $3.17 \pm 1.4^{\star}$ & $7.55 \pm 1.0$ & $7.55 \pm 1.1$ \\
\hline Fasting glucose $\mathrm{a}^{\mathrm{a}}$ & $43(30.7 \%)$ & $5.62 \pm 2.1$ & $2.68 \pm 0.3^{*}$ & $7.37 \pm 0.9$ & $7.64 \pm 1.1$ \\
\hline Smoking & $98(70 \%)$ & $3.59 \pm 1.8$ & $3.48 \pm 1.5$ & $7.56 \pm 1.1$ & $7.46 \pm 1.0$ \\
\hline LDL-C & $103(73.6 \%)$ & $3.81 \pm 1.9$ & $2.95 \pm 1.1^{\star}$ & $7.69 \pm 1.1$ & $7.17 \pm 1.0^{*}$ \\
\hline
\end{tabular}

a Abnormal cut offs according to IDF criteria (see "Methods" section).

${ }^{b}$ Abnormal cut off: $L D L-C>100 \mathrm{mg} / \mathrm{dL}$.

${ }^{*} p<0.05$ for the difference between presence or absence.

\begin{tabular}{|c|c|c|c|}
\hline & \multicolumn{2}{|c|}{ Factor loading } & \multirow{2}{*}{ Communality } \\
\hline & 1 & 2 & \\
\hline Fasting glucose & 0.887 & 0.304 & 0.76 \\
\hline Fasting insulin & 0.907 & & 0.76 \\
\hline HDL-C & & -0.513 & 0.57 \\
\hline LDL-C & & 0.543 & 0.58 \\
\hline Triglycerides & & 0.600 & 0.57 \\
\hline Eigen values & 3.928 & 2.314 & \\
\hline$\%$ of variance & 32.97 & 23.13 & \\
\hline
\end{tabular}

Loadings $<0.30$ are omitted. 


\section{DISCUSSION}

\section{Association between glycemic control and biochemical parameters}

In the next century more than $100,000,000$ individuals will be obese and, of these, more than $15,000,000$ will become diabetic. The mechanism through which obesity causes diabetes remains obscure, but it is known that obesity is associated with insulin resistance, and that effective compensatory hiperinsulinemia initially maintains blood glucose levels within normal range (13). However, after some time, the ability of pancreatic $\beta$ cells to compensate for increasing insulin resistance may flag, the so-called $\beta$-cell failure.

Obesity, as well as diabetes, is associated with dyslipidemia, characterized by an increase in circulating free fatty acids (FFA), accumulation of triglycerides in peripheral tissues and changes in lipoprotein profile (13-16). High plasma levels of FFA are related with excessive accumulation of fat in pancreatic $\beta$-cell, and it leads to cellular dysfunction, called lipotoxicity (1719). The lipotoxicity is the result of a constellation of islet derangements, like the decreased $\beta$-cell GLUT- 2 expression (20), enhanced nitric oxide formation (21), impaired $\beta$-cell function (20) and apoptosis of a substantial subgroup of $\beta$ cells (18).

In our results, a high level of triglycerides (upper tertile) was associated with insulin resistance (Table 1), a known fact, and with a poor glycemic control (Figure 1 and Tables 1, 2 and 3). Like said before, the glycemic control depends mainly on the degree of residual pancreatic beta-cell function and insulin sensitivity (5), and the TG is associated with both. The pancreatic islets exhibit an increased incorporation of $\left[{ }^{3} \mathrm{H}\right]$ palmitate into triglycerides, and this is believed to be a major factor in the overaccumulation of fat, given the high levels of circulating fatty acids and triglycerides that characterizes obesity (22-23). A normal pancreatic islet contains approximately $24 \mathrm{ng}$ of triglycerides and this number can increase to $990 \mathrm{ng}$ in the islets of obese, leptinresistance Zucker diabetic fatty rats (24), the animal model used to study the mechanisms of $\beta$-cell failure in obesity.

In our study, a poor glycemic control was associated with high levels of VLDL-C and LDL-C and with a low level of HDL-C too (Table 1). It was demonstrated that purified human very low-density lipoprotein and lowdensity lipoprotein particles reduced insulin mRNA levels and $\beta$-cell proliferation and were proapoptotic, whereas high-density lipoprotein protected $\beta$-cells against these proapoptotic effects. These protective effects were mediated, at least partially, by inhibition of caspase- 3 cleavage and activation of Akt/protein kinase $\mathrm{B}$, whereas proapoptotic lipoproteins seem to act via c-Jun N-terminal kinase (25). These results are highly suggestive that the changes in lipoprotein profile observed in obesity could contribute to the pathogenesis and progression of $\beta$-cell failure (14).

Other proposed pathway of lipotoxicity is the enhanced expression of sterol regulatory element-binding protein-lc (SREBP-lc) and lipogenic genes such as fatty acid synthase (FAS) and acetyl-coenzyme A carboxylase (ACC) in pancreatic islets of ZDF rats (26). The SREBP-lc, through a direct interaction with cis-acting element, regulate the expression of the uncoupling protein-2 (UCP-2), which has the SRE sequence on its promoter region. It has been shown that the expression of UCP-2, which has been involved in dissipation of the mitochondrial proton gradient, was enhanced in the pancreatic islets of lipotoxicity models (15).

In obesity, the flux of FFA from adipocytes into islets is greatly enhanced in proportion to the obesity. Because leptin levels, which are known for their ability to lower the TG content of isolated islets by reducing esterification and by increasing oxidation of FFA, also rise proportionately to the obesity, it is suggested that they prevent excessive accumulation of triglycerides and lipotoxicity. However, if the islet leptin receptors are defective or the sensitivity of islets to leptin is diminished by postereceptor defects, like in morbid obesity, islet fat content may rise to a lipotoxic level, in which case adipogenic diabetes will ensue (19).

The obesity is also associated with a pro-inflammatory status that provides a potential link between insulin resistance and endothelial and beta cell dysfunction. The visceral and subcutaneous adipose tissues are the major source of cytokines/adipokines, which are low molecular weight proteins that participate in inflammation and immune response. Thus, increased adipose tissue mass is associated with alteration in adipokine production as over expression of tumor necrosis factor $\alpha$, plasminogen activator inhibitor 1 and interleukin 6 (14).

In summary, the role of plasmatic lipids in glycemic control is well established. We believe that the results shown in Tables 2 and 3 demonstrate that the use of TG levels and fasting insulin and glucose levels offer a reasonable degree of clinical utility. Of these alternatives, the plasma triglycerides levels are the metabolic 
markers most closely related to poor glycemic control. In addition, this marker is said to increase CVD (27) risk as well as to be associated with insulin resistance (28). Thus, if the goal is to identify those insulin-resistant with poor glycemic control individuals who are at risk for CVD, this marker may offer some advantage over the others.

\section{Assessment of cardiometabolic risks}

In this population-based study, we found that, before RYGBP, $78.5 \%$ of morbidly obese patients had at least one cardiometabolic risk factor, and that these factors clustered into two groups. The atherogenic dyslipidemia (high TG and low HDL-C) is the commonest cardiometabolic abnormalities. In this population, the BMI is higher than the normal weight population and relatively constant, hence, the obesity did not constitute an important factor in our patients. The central characteristics of a unified metabolic syndrome included hyperglycemia (reflecting insulin resistance) and dyslipidemia. The glucose intolerance was linked to the dyslipidemia through mutual associations with fasting glucose levels.

Like showed in table 5, HOMA-IR values were significantly higher in subjects with cardiometabolic abnormalities. It corroborates the idea that insulin resistance, although it is not the only, is considered to be an important contributor to cardiometabolic risk. Recent studies show that obesity, central obesity, high insulin response and insulin resistance, all independently and partially, contribute to cardiometabolic risk (29). The glycemic control, assessed by $\mathrm{HbA}_{\mathrm{lc}}$, has no correlation with the presence of cardiometabolic risk in this population but, certainly, its control constitutes the basis of treatment of these patients, aiming at the prevention of diabetes and cardiovascular diseases (30).

Intercorrelation of variables introduces collinearity into predictive statistical models, producing unreliable estimates and making it difficult to ascertain which variables represent the dominant physiological processes (31). Factor analysis has long been used in psychometric research to deal with this problem and has been an increasing use to analyze physiological relationships (10). In our results, factor analysis does not imply that insulin resistance causes dyslipidemia; rather, it demonstrates that these two phenotypes are very closely associated and defines a unique physiological domain.
In summary, factor analyses identify two independent factors underlying clustering of the basic cardiometabolic risk variables. A hyperglycemia and dyslipidemia define two distinct physiological domains linked together through mutual associations with fasting glucose levels. In our patients, insulin resistance plays an important role in the prevalence of cardiometabolic risk variables and the higher prevalence of atherogenic dyslipidemia makes necessary the adoption of measures for prevention of cardiovascular diseases.

Some limitations are present in our study: the first is that HOMA-IR is not the gold standard in the evaluation of insulin resistance. Nevertheless, this index correlates moderately well with insulin resistance as measured by hyperinsulinemic euglycemic clamp, which is considered to be the gold standard in the evaluation of insulin resistance (32). Thus, several large population studies have shown that the application of HOMA-IR is a good method for assessing insulin resistance across a range of glucose tolerance from normal to diabetes (33). A second limitation is that the study sample consisted primarily of white Brazilians, and the ability of the same metabolic markers or cut-points to predict poor glycemic control in overweight individuals of other ethnicities is yet to be proven.

Disclosure: no potential conflict of interest relevant to this article was reported.

\section{REFERENCES}

1. American Diabetes Association. Standards of medical care in diabetes. Position Statement Diabetes Care. 2007;30:S4-S41.

2. UK Prospective Diabetes Study (UKPDS) Group. Intensive bloodglucose control with sulphonylureas or insulin compared with conventional treatment and risk of complications in patients with type 2 diabetes (UKPDS 33). Lancet. 1998;352(9131):837-53.

3. [No authors listed]. The absence of a glycemic threshold for the development of long-term complications: the perspective of the diabetes control and complications trial. Diabetes. 1996;45(10):1289-98.

4. Hubert HB, Feinleib M, McNamara PM, Castelli WP. Obesity as an independent risk factor for cardiovascular disease: a 26-year follow-up of participants in the Framingham Heart Study. Circulation. 1983;67(5):968-77.

5. Dansuntornwong $B$, Chanprasertyothin $S$, Jongjaroenprasert W, Ngarmukos C, Bunnag P, Puavilai G, et al. The relation between parameters from homeostasis model assessment and glycemic control in type 2 diabetes. J Med Assoc Thai. 2007;90(11):2284-90.

6. Bonora E, Targher G, Alberiche M, Formentini G, Calcaterra F, Lombardi $S$, et al. Predictors of insulin sensitivity in type 2 diabetes mellitus. Diabet Med. 2002;19:535-42.

7. McLaughlin T, Abbasi F, Cheal K, Chu J, Lamendola C, Reaven G. Use of metabolic markers to identify overweight individuals who are insulin resistant. Ann Intern Med. 2003;139(10):802-9. 
8. Executive summary of the third report of the National Cholesterol Education Program (NCEP) Expert Panel on Detection, evaluation and treatment of high blood cholesterol in adults (Adult Treatment Panel III). JAMA. 2001;285:2486-97.

9. Guerrero-Romero F, Rodríguez-Morán M. Concordance between the 2005 International Diabetes Federation definition for diagnosing metabolic syndrome with the National Cholesterol Education Program Adult Treatment Panel III and the World Health Organization definitions. Diabetes Care. 2005;28(10):2588-9.

10. Meigs JB, D'Agostino RB, Wilson PW, Cupples LA, Nathan DM, Singer DE. Risk variable clustering in the insulin resistance syndrome: the framingham offspring study. Diabetes. 1997;46(10):1594-600.

11. Levy JC, Matthews DR, Hermans MP. Correct homeostasis model assessment (HOMA) evaluation uses the computer program. Diabetes Care. 1998;21(12):2191-2

12. Cureton EE, D'Agostino RB. Factor analyses: an applied approach. Lawrence Eribaum Associates Hillsdale NJ; 1983.

13. Reaven GM. The fourth musketeer: from Alexandre Dumas to Claude Bernard. Diabetologia. 1995;38:3-13.

14. Wajchenberg BL. $\beta$-Cell failure in diabetes and preservation by clinical treatment. Endocr Rev. 2007;28(2):187-218.

15. Yamashita T, Eto K, Okazaki Y, Yamashita S, Yamauchi T, Sekine N et al. Role of uncoupling protein-2 up-regulation and triglyceride accumulation in impaired glucose-stimulated insulin secretion in a $\beta$-cell lipotoxicity model overexpressing sterol regulatory element-binding protein-1c. Endocrinology. 2004;145(8):3566-77.

16. Fraze E, Donner CC, Swislocki AL, ChiouYA, Chen YD, Reaven GM. Ambient plasma free fatty acid concentrations in noninsulin-dependent diabetes mellitus: evidence for insulin resistance. J Clin Endocrinol Metab. 1985;61(5):807-11.

17. Unger RH. Lipotoxicity in the pathogenesis of obesity-dependent NIDDM. Genetic and clinical implications. Diabetes. 1995;44(8):863-70.

18. Shimabukuro M, Zhou YT, Levi M, Unger RH. Fatty acid-induced $\beta$-cell apoptosis: A link between obesity and diabetes. Proc Natl Acad Sci USA. 1998;95(5):2498-502.

19. ZhouYT, Shimabukuro M, Wang MY, LeeY, Higa M, Milburn JL, et al. Role of peroxisome proliferator-activated receptor $\alpha$ in disease of pancreatic $\beta$ cells. Proc Natl Acad Sci USA. 1998;95(15):8898-903.

20. Johnson JH, Ogawa A, Chen L, et al. Underexpression of beta cell high $\mathrm{Km}$ glucose transporters in noninsulin-dependent diabetes. Science. 1990;250:546-9.
21. Shimabukuro $M$, Ohneda $M$, Lee $Y$, Unger $R H$. Role of nitric oxide in obesity-induced beta cell disease. J Clin Invest. 1997;100(2):290-5.

22. Zhou YT, Shimabukuro M, LeeY, Koyama K, Higa M, FergusonT, et al. Enhanced de novo lipogenesis in the leptin-unresponsive pancreatic islets of prediabetic zucker diabetic fatty rats: Role in the pathogenesis of lipotoxic diabetes. Diabetes. 1998;47(12):1904-8.

23. Lee $Y$, Hirose H, Zhou YT, Esser V, McGarry JD, Unger RH. Increased lipogenic capacity of islets of obese rats: a role in the pathogenesis of NIDDM. Diabetes. 1997;46(3):408-13.

24. Zhou YT, Shimabukuro M, Koyama K, LeeY, Wang MY, Trieu F, et al. Induction by leptin of uncoupling protein-2 and enzymes of fatty acid oxidation. Proc Natl Acad Sci USA. 1997;94(12):6386-90.

25. Roehrich ME, Mooser V, Lenain V, Herz J, Nimpf J, Azhar S, et al. Insulin-secreting $\beta$-cell dysfunction induced by human lipoproteins. J Biol Chem. 2003;278(25):18368-75.

26. KakumaT, LeeY, Higa M, Wang Z, Pan W, Shimomura I, et al. Leptin, troglitazone and the expression of sterol regulatory element binding proteins in liver and pancreatic islets. Proc Natl Acad Sci USA. 2000;97(15):8536-41.

27. Hokanson JE, Austin MA. Plasma triglyceride level is a risk factor for cardiovascular disease independent of high-density lipoprotein cholesterol level: a meta-analysis of population-based prospective studies. J Cardiovasc Risk. 1996;3(2):213-9.

28. Laws A, Reaven GM. Evidence for an independent relationship between insulin resistance and fasting plasma HDL-cholesterol, triglyceride and insulin concentrations. J Intern Med. 1992;231(1):25-30.

29. Goldfarb B. Insulin resistance: one of many players in cardiometabolic risk. DOC News 2007;4:7.

30. Hoerger TJ, Ahmann AJ. The impact of diabetes and associated cardiometabolic risk factors on members: Strategies for optimizing outcomes. J Manag Care Pharm. 2008;14(Suppl 1):S2-14.

31. Gordon T. Hazards in the use of the logistic function with special reference to data from prospective cardiovascular studies. J Chron Dis. 1974;27(3):97-102.

32. DeFronzo RA, Tobin JD, Andres R. Glucose clamp technique: a method for quantifying insulin secretion and resistance. Am J Physiol. 1979;237(3):E214-223.

33. Haffner SM, Kennedy E, Gonzalez C, Stern MP, Miettinen H. A prospective analysis of the HOMA model. The Mexico City Diabetes Study. Diabetes Care. 1996;19(10):1138-41. 